\title{
Analisis Profesi, Persyaratan Kerja dan hasil kerja akuntan terhadap Mahasiswa di Kota Batam
}

\author{
Jenniver $^{1}$ Mortigor Afrizal Purba ${ }^{2}$ \\ Program Studi Akuntansi, Universitas Putera Batam \\ pb180810038@upbatam.ac.id, mortigor@upbatam.ac.id
}

*Corresponding Author

Diajukan : 18 Nopember 2022

Disetujui : 5 Desember 2021

Dipublikasi : 1 Januari 2022

\begin{abstract}
The purpose of this research is to examine accounting students in Batam City who have a career in public accounting which measures the accounting profession, job requirements and work results of accountants. The extent to which the accounting profession, accountants job requirements and accountants' work results affect the career choices of students in the public accounting sector. Career is an important thing that becomes a person's goal to reach a higher level in a job. This study used a sample of 310 undergraduate students from various universities in Batam City. The questionnaire consists of 21 question items which use a Likert scale ranging from strongly disagree to strongly agree. The distribution of the questionnaire was completed at the end of October 2021. The data used descriptive statistics that had been collected were entered and analyzed using the SPSS version 26 program. Public accountants have a working profession so that researchers found that accounting was rated higher by respondents in relation to the work of accountants as a profession. boring, routine and monotonous. Then, in connection with the choice of a career as a public accountant from Batam City students, it shows that the choice of a career as a public accountant is more dominant than other accountants such as corporate accountants. Even with the limitations of the research it will still be useful for policy makers to create new or new ideas and modify their strategies with respect to the problems identified.
\end{abstract}

Keywords: profession; public accountant job requirement; accountants work; student

\section{PENDAHULUAN}

Pada umumnya, akuntansi merupakan suatu proses yang berusul dengan penyajian data, pencatatan transaksi keuangan, pencatatan atau pendaftaran, penggolongan, mengolah menurut Itan \& Gabriela (2021). Menurut Itan \& Gabriela (2021) akuntansi dimulai pada saat sistem perdagangan di dunia masih menggunakan sistem tukar menukar barang tidak menggunakan uang atau disebut perdagangan barter. Menurut Purba \& Yando (2020) Jika dapat diucapkan maka dalam bisnis modern zaman sekarang tidak ada tanpa akuntansi atau akuntan dan berbagai penelitian telah menunjukkan bahwa robot lebih baik dalam tugas-tugas akuntansi daripada manusia. Menurut Karina \& Wijaya (2021) Profesi akuntan adalah sebuah pekerjaan yang mengandalkan kemampuan atau keahlian dalam bidang akuntansi. Termasuk juga sektor pekerjaan akuntan publik, akuntan perusahaan, akuntan keuangan/akuntan dagang, akuntan pemerintah dan akuntan pendidikan. Akuntan publik berperan menghubungkan antara pihak manajemen dengan pemilik atau yang mengendalikan suatu bidang usaha. Menurut Setiany, E., Hartoko, S., Suhardjanto, D., \& Honggowati (2018) akuntan publik merupakan profesi yang memberikan jasa dan tergantung pada jasa atas permintaan dari pelanggan.

Pada profesi akuntan publik ada persyaratan kerja yang wajib terpenuhi. Menurut Itan \& Gabriela (2021) Persyaratan kerja adalah persyaratan yang wajib terpenuhi oleh setiap orang agar dapat diterima sebagai pegawai atau karyawan. Persyaratan kerja berasal dari kata dasar persyaratan. Lingkungan kerja merupakan pertimbangan dari tanggapan variabel atau tanggapan positif tentang hasil kerja akuntan. Untuk menghasilkan pekerjaan yang lebih baik, profesi 
akuntan publik harus memiliki pandangan, daya, banyak peluang atau periode, dan terjadi saingan yang tinggi antara karyawati atau pegawai. Menurut Itan \& Gabriela (2021) pandangan mahasiswa akuntan terhadap hasil pekerjaan akuntansi yang positif dari pertanyaan berupa pendapatan seperti gaji, keuangan lainnya insentif, tunjangan, bonus dan dana pensiun. Karir dapat disebut sebagai suatu penempatan ke pangkatan yang mempunyai kewajiban yang tinggi dari sebelum di lewati setiap orang selama hidupnya. Menurut Handoko (2014), karir sebagai pengalihan ke jabatan yang mewajibkan tanggung jawab lebih, karir sebagai arahan pekerjaan yang membuat sesuatu sistem kemajuan penataan yang jelas dan karir sebagai sejarah pekerjaan setiap orang dengan kedudukan yang dipegangnya selama kehidupan kerjanya.

Pada penelitian ini ada beberapa yang perlu di perhatikan menurut Itan \& Gabriela (2021) informasi negatif mengenai mahasiswa akuntan kurang percaya diri dikarenakan kurang dukungan atau motivasi dari keluarga dan teman, tantangan dan persyaratan dalam memilih profesi akuntan publik. Dalam pemilihan karir tersebut juga tergantung pada ketertarikan mahasiswa akuntansi yang ingin menjadi akuntan publik, banyak yang kita ketahui bahwa kerja profesi akuntan tersebut lumayan membosankan, dan perlu ketelitian yang cukup tinggi, sehingga banyak faktor menjadi pertimbangan bagi mahasiswa akuntansi dalam memilih maupun memulai karirnya. Finansial atau gaji yang didapatkan akan selalu jadi perhatikan, maka dengan hasil pekerjaan akuntan berupa gaji yang tinggi dan pengakuan dimata masyarakat serta pengembangan dan pelatihan yang selalu didambakan oleh mahasiswa akuntansi akan menarik perhatian mahasiswa untuk berprofesi sebagai seorang akuntan. Selain mendapatkan gaji yang tinggi, namun berprofesi sebagai akuntan juga mendapatkan pengalaman yang banyak dan pengembangan dan pelatihan diri ke tahap yang lebih baik dan professional.

Boateng (2019) melakukan penelitian dengan tujuan menguji persepsi mahasiswa Akuntansi Tersier Cina tentang Certified Akuntan Publik dan sejauh mana persepsi mempengaruhi pilihan pekerjaan karir mereka antara publik dan sektor akuntansi swasta. Faktor hasil pekerjaan akuntan berpengaruh signifikan terhadap profesi akuntan, pada mahasiswa akuntansi mengutamakan hasil yang didapatkan atas pekerjannya sedangkan penelitian penulis bahwa mahasiswa akuntansi sangat setuju pada persyaratan kerja akuntan yang sangat sulit untuk menjadi akuntan publik.

Setelah di telitikan oleh peneliti sebelumnya dan masih samarnya mahasiswa akuntansi terhadap pemilihan karir sebagai akuntan publik. Penelitian ini bertujuan untuk memberitahukan apakah mahasiswa dalam profesi akuntan berupa gambaran, persyaratan kerja akuntan dan hasil kerja akuntan berupa penghargaan finansial berpengaruh terhadap mahasiswa di kota Batam

\section{STUDI LITERATUR}

\section{Teori Pengaruh Profesi Akuntan Terhadap Mahasiswa di Kota Batam}

Profesi akuntan adalah sebuah pekerjaan yang mengandalkan kemampuan atau keahlian dalam bidang akuntansi Itan \& Gabriela (2021). Pada profesi akuntan ada gambaran dipikiran kita ketika mengatakan profesi akuntan yaitu suatu pekerjaan berkaitan sama bilangan dan keuangan. Untuk menjadi seorang akuntan yang professional merupakan niat yang cukup banyak oleh sebagai mahasiswa karena sudah mendalami ilmu tentang akuntansi, namun ada sebagian mahasiswa akuntansi kurang berani pada diri sendiri atas kemampuannya agar dapat menjadi akuntan professional dan kurang dukungan pada keluarga dan teman.

$\mathrm{H}_{1}$ : Profesi akuntan berpengaruh signifikan terhadap mahasiswa di kota Batam.

\section{Teori Pengaruh Persyaratan Kerja Akuntan Terhadap Mahasiswa di Kota Batam}

Boateng (2019) adalah Penelitian sebelumnya yang menampilkan pada variabel persyaratan pekerjaan akuntan tidak berpengaruh signifikan terhadap profesi akuntan yang menyimpulkan mahasiswa akuntansi merasa perlu banyak waktu, dana, peraturan yang tinggi yang menjadi hambatan terbesar. Setiap profesi memiliki aturan dan persyaratan professional seperti Standar Akuntansi Keuangan untuk Entitas Tanpa Akuntansi Publik (SAK-ETAP), PSAK Syariah, Standar Akuntansi Keuangan (SAK) yang terdiri dari Pernyataan Standar Akuntansi Keuangan - International Financial Report Standard (PSAK-IFRS), dan Standar Akuntansi 
Pemerintah (SAP). Di mana pada setiap pelaporan keuangan dan pencatatan wajib menirukan dan sama dengan standar yang berlaku atau peraturan.

$\mathrm{H}_{2}$ : Persyaratan Kerja Akuntan berpengaruh signifikan terhadap mahasiswa di kota Batam.

\section{Teori Pengaruh Hasil Kerja Akuntan Terhadap Mahasiswa di Kota Batam}

Penelitian Karina \& Wijaya (2021) mengenai hasil pekerjaan akuntan yaitu pandangan mahasiswa akuntan terhadap hasil pekerjaan akuntansi yang positif dari pertanyaan berupa pendapatan seperti gaji, keuangan lainnya insentif, tunjangan, bonus dan dana pensiun dan hasil pekerjaan lainnya berupa kesempatan dalam peningkatan karir, pemuasan pribadi, persaksian dan reputasi nama baik, dan lain-lain. Hasil kerja akuntan yang di dapatkan oleh profesi akuntan adalah penghargaan finansial. Penghargaan finansial adalah hasil yang didapatkan sebagai kontraprestasi dari pekerjaan yang lebih dipercayakan oleh sebagian besar perusahaan yang menjadi daya tarik utama dalam memberikan kepuasan untuk karyawannya.

$\mathrm{H}_{3}$ : Hasil Kerja akuntan berpengaruh signifikan terhadap mahasiswa di kota Batam.

\section{Mahasiswa Akuntansi Dalam Memilih Karir Sebagai Akuntan Publik}

Mahasiswa akuntansi yang berminat dalam memilih berkarir menjadi akuntan publik memperlihatkan minat dan kemauan mahasiswa akuntansi untuk menentukkan karirnya menjadi akuntan publik. Variabel dependen pada penelitian ini ialah minat mahasiswa akuntansi dalam pemilihan karir menjadi akuntan publik.

\section{Penelitian Terdahulu}

Hasil penelitian oleh Karina \& Wijaya (2021) melakukan penelitian terkait analisis pengaruh persepsi mahasiswa terhadap profesi akuntan di kota Batam dengan variabel independen yaitu sikap negative akuntan, gambar profesi akuntan, persyaratan kerja akuntan, hasil kerja akuntan terhadap satu variabel dependennya yaitu minat mahasiswa terhadap profesi akuntan. Pada penelitian ini menampilkan hasil variabel gambar profesi akuntan, persyaratan kerja akuntan dan hasil kerja akuntan berpengaruh secara signifikan positif terhadap profesi akuntan.

Hasil penelitian oleh Kristina \& Argo Putra Prima (2020) melakukan penelitian terkait analisis faktor-faktor yang mempengaruhi pemilihan karir sebagai akuntan publik pada mahasiswa akuntansi di kota batam dari hasil uji variabel penghargaan finansial pengaruh signifikan terhadap variabel dependen yaitu mahasiswa akuntansi memilih karir sebagai akuntan publik di kota Batam.

Mirawati (2017) melakukan penelitian terkait Pengaruh Motivasi Terhadap Minat Pemilihan Karir Mahasiswa Akuntansi Sebagai Akuntan Publik dengan variabel independen yaitu motivasi pasar kerja (X1), motivasi ekonomi (X2), lingkungan kerja (X3) dan kepribadian individu (X4) terhadap satu variabel dependennya adalah minat pemilihan karir akuntan publik (Y). Pada penelitian ini menampilkan hasil variabel motivasi ekonomi yang dimiliki berupa penghargaan finansial dan menunjukan bahwa motivasi eknomomi berpengaruh terhadap mahasiswa pemilihan karir sebagai akuntan publik.

Hasil penelitian oleh Astuti \& Andri Waskita Aji (2021) melakukan penelitian terkait Terhadap Minat Mahasiswa Akuntansi Menjadi Akuntan Publik (Studi Kasus Pada Mahasiswa Jurusan Akuntansi Program S1 Universitas Sarjana wiyata Tamansiswa Yogyakarta). Penelitian ini mengungkapkan hasil $\mathrm{H}_{1}$ motivasi ekonomi tidak terdapat pengaruh terhadap minat mahasiswa akuntansi menjadi akuntan publik, kemudian Hasil $\mathrm{H}_{2}$ dan $\mathrm{H}_{3}$ bahwa motivasi karir berupa penghargaan finansial dan persyaratan akuntan publik terdapat pengaruh positif terhadap minat mahasiswa akuntansi menjadi akuntan publik.

Hasil penelitian oleh Alvin Juliansah \& Rossje V Suryaputri (2016) melakukan penelitian terkait faktor-faktor yang mempengaruhi pemilihan karir sebagai profesi akuntan publik bagi mahasiswa akuntansi yang menampilkan hasil variabel Intrinsik Pekerjaan, Penghargaan Finansial, Pertimbangan Pasar Kerja, Nilai-Nilai Sosial, dan Personalitas berpengaruh positif terhadap Pemilihan Karir Menjadi Akuntan Publik bagi mahasiswa akuntansi sedangkan 
Lingkungan Kerja berpengaruh negatif terhadap Pemilihan Karir Menjadi Akuntan Publik bagi mahasiswa akuntansi.

Danar Sutopo Sidig \& Andar Ramona Sinaga (2020) Mengungkapkan bahwa What Explains Students' Intentions To Pursue Public Accountants As a Career?. Accordingly, we propose the following hypothesis H1: Indonesian accounting students who believe public accountant profession can improve their social prestige are more likely to pursue such careers. Therefore, we propose the following hypothesis: H2: Indonesian accounting students who believe public accountant profession can improve their earnings potential are more likely to pursue such careers. Thus, based on these past studies, this research proposes the following hypothesis: H3: Indonesian accounting students who perceived higher positivities towards public accountants' job-related factors are more likely to pursue such careers. Consequently, based on the TPB and these prior studies, this research proposes the following hypothesis: H4: Indonesian accounting students on which other people can influence to become public accountants are more likely to pursue such careers. Based on this current practice, this study proposes the following hypothesis: H5: Indonesian accounting students believe the less difficult to acquire and maintain public accountant qualifications, the more likely they pursue such careers.

Hasil penelitian oleh Itan \& Gabriela (2021) melakukan penelitian terkait Persepsi Mahasiswa Akuntansi Terhadap Profesi Akuntan di Kota Batam dengan variabel independen yaitu sikap negative akuntan, gambar profesi akuntan, persyaratan kerja akuntan, hasil kerja akuntan terhadap satu variabel dependennya yaitu minat mahasiswa terhadap profesi akuntan. ). Pada penelitian ini menampilkan hasil variabel gambar profesi akuntan, persyaratan kerja akuntan dan hasil kerja akuntan berpengaruh secara signifikan positif terhadap profesi akuntan.

\section{METODE}

Desain penelitian merupakan gambaran yang bertujuan untuk menampilkan penelitian yang didefinisikan dan berfungsi sebagai pedoman atau tata cara untuk peneliti baru dalam memproseskan pengerjaan riset yang menggunakan jenis penelitian kuantitatif.

\section{Populasi}

Pada penelitian ini di ambil dari data Pangkalan Data Pendidikan Tinggi (PDDikti) dengan link https://pddikti.kemdikbud.go.id/.

Tabel 1. Populasi

\begin{tabular}{|c|l|c|}
\hline No. & \multicolumn{1}{|c|}{ Nama Perguruan Tinggi } & $\begin{array}{c}\text { Jumlah Mahasiswa } \\
\text { Akuntansi Terakhir }\end{array}$ \\
\hline 1 & Politeknik Negeri Batam & 450 \\
\hline 2 & Universitas Internasional Batam & 476 \\
\hline 3 & Universitas Universal & 138 \\
\hline 4 & Universitas Ibnu Sina & 44 \\
\hline 5 & Universitas Batam & 115 \\
\hline \multicolumn{2}{|c|}{ Jumlah } & 1223 \\
\hline \multicolumn{2}{|c|}{ Sumber: Pangkalan Data Pendidikan Tinggi (PDDikti) (2021) }
\end{tabular}

\section{Sampel}

Menurut Sugiyono (2010) Sampel, juga dikenal sebagai sampling, adalah persentase dari jumlah dan karakteristik populasi. teknik yang digunakan untuk menentukan sampel untuk penelitian ini adalah teknik simple random sampling. Nilai toleransi ditentukan sebesar 5\% atau kurang dari 0,05. Berdasarkan hasil perhitungan sampel di atas adalah 301.4 dan di bulatkan menjadi sebanyak 302 sampel. Maka jumlah sampel yang didapatkan minimal 302 responden agar sampel yang dipakai lebih representatif sebagai mahasiswa akuntansi dalam memilih karir sebagai akuntan publik di Kota Batam.

\section{Teknik Pengumpulan Data}


Owner: Riset \& Jurnal Akuntansi

e-ISSN : 2548-9224 | p-ISSN : 2548-7507

Volume 6 Nomor 1, Januari 2022

DOI : https://doi.org/10.33395/owner.v6i1.550

Data diperoleh dan dikumpulkan melalui pemberian pertanyaan kepada responden melalui penyebaran kuesioner.

\section{Statistik Deskriptif}

HASIL

Menurut Ghozali (2016:19) analisis statistik deskriptif merupakan penyampaian tinjauan atau deskripsi yang pendek atau singkat mengenai data rata-rata, standar deviasi, maksimum dan minimum.

Tabel 2. Hasil Uji Statistik Deskriptif

Descriptive Statistics

\begin{tabular}{lrrrrr}
\hline & N & Minimum & Maximum & Mean & Std. Deviation \\
Profesi_Akuntan & 310 & 11 & 20 & 16,70 & 2,138 \\
Persyaratan_Kerja_Akuntan & 310 & 15 & 30 & 23,97 & 3,260 \\
Hasil_Kerja_Akuntan & 310 & 11 & 25 & 19,08 & 3,169 \\
Mahasiswa & 310 & 15 & 30 & 24,31 & 3,334 \\
Valid N (listwise) & 310 & & & & \\
\hline
\end{tabular}

Sumber : Lampiran Output SPSS 26, 2021

Berdasarkan data, variabel profesi akuntan, persyaratan kerja, hasil kerja akuntan dan mahasiswa memiliki nilai minimal senilai $11,15,11$ dan 15 , kemudian memiliki nilai maksimum masing-masing senilai 20, 30, 25, dan 30. Dapat terlihat bahwa nilai standar deviasi dari variabel profesi akuntan, persyaratan kerja, hasil kerja akuntan dan mahasiswa adalah 2,138, 3,260, dan 3,169 , dan 3,334. Nilai rata-rata dari variabel profesi akuntan, persyaratan kerja, hasil kerja akuntan dan mahasiswa adalah 16,70, 23,97, 19,08, dan 24,31.

\section{Uji Kualitas Data}

\section{Uji Validitas}

Menurut Ghozali (2018:51) Uji validitas dilakukan agar mengerti apakah kuesioner valid atau tidak. Kuesioner dinyatakan gagal ketika pertanyaan diidentifikasi pada indeks kuesioner. Menurut Sugiyono (2018:202) item pernyataan valid atau gagal dapat dicermati dari kaitan terhadap skor total, mendapatkan hasil perhitungan dengan menyambung skor item dengan skor total.

Tabel 3. Hasil Uji Validitas 
Owner: Riset \& Jurnal Akuntansi

e-ISSN : 2548-9224 | p-ISSN : 2548-7507

Volume 6 Nomor 1, Januari 2022

DOI : https://doi.org/10.33395/owner.v6i1.550

\begin{tabular}{|c|c|c|c|}
\hline Keterangan & R hitung & $\mathrm{R}$ tabel & Hasil \\
\hline \multicolumn{4}{|c|}{ Profesi Akuntan } \\
\hline $\mathrm{X} 1.1$ & 0,706 & 0,111 & Valid \\
\hline $\mathrm{X} 1.2$ & 0,736 & 0,111 & Valid \\
\hline $\mathrm{X} 1.3$ & 0,680 & 0,111 & Valid \\
\hline $\mathrm{X} 1.4$ & 0,645 & 0,111 & Valid \\
\hline \multicolumn{4}{|c|}{$\begin{array}{c}\text { Persyaratan Kerja } \\
\text { Akuntan }\end{array}$} \\
\hline $\mathrm{X} 2.1$ & 0,345 & 0,111 & Valid \\
\hline $\mathrm{X} 2.2$ & 0,558 & 0,111 & Valid \\
\hline $\mathrm{X} 2.3$ & 0,773 & 0,111 & Valid \\
\hline $\mathrm{X} 2.4$ & 0,662 & 0,111 & Valid \\
\hline $\mathrm{X} 2.5$ & 0,833 & 0,111 & Valid \\
\hline $\mathrm{X} 2.6$ & 0,842 & 0,111 & Valid \\
\hline \multicolumn{4}{|c|}{ Hasil Kerja Akuntan } \\
\hline $\mathrm{X} 3.1$ & 0,629 & 0,111 & Valid \\
\hline $\mathrm{X} 3.2$ & 0,760 & 0,111 & Valid \\
\hline X3.3 & 0,839 & 0,111 & Valid \\
\hline $\mathrm{X} 3.4$ & 0,852 & 0,111 & Valid \\
\hline $\mathrm{X} 3.5$ & 0,777 & 0,111 & Valid \\
\hline \multicolumn{4}{|l|}{ Mahasiswa } \\
\hline Y.1 & 0,603 & 0,111 & Valid \\
\hline Y.2 & 0,745 & 0,111 & Valid \\
\hline Y.3 & 0,761 & 0,111 & Valid \\
\hline Y.4 & 0,797 & 0,111 & Valid \\
\hline Y.5 & 0,766 & 0,111 & Valid \\
\hline Y.6 & 0,743 & 0,111 & Valid \\
\hline
\end{tabular}

Sumber : Data primer diolah (2021)

Terlihat setiap indikator masing-masing variabel menunjukkan bahwa $r$ hitung $>r$ tabel dan menunjukkan hasil yang signifikan. Sehingga bisa disimpulkan semua item pernyataan dinyatakan valid.

\section{Uji Reliabilitas}

Menurut Ghozali (2018:45) mengemukakan bahwa reliabilitas ialah sebagai alat mengukur kuesioner yang menunjukkan suatu variabel maupun struktur. Kriteria penilaian untuk pengujian reabilitas adalah Apabila angka CronbachAlpha $>0,60 \%$ sehingga data tersebut reliable dan Jika nilai CronbachAlpha $<0,60 \%$ maka data tersebut tidak reliable.

Tabel 4. Hasil Uji Reliabilitas untuk Profesi Akuntan X1

Cronbach's

Alpha $\quad \mathrm{N}$ of Items

,603 4

Sumber : Lampiran Output SPSS 26, 2021

Tabel 5. Hasil Uji Reliabilitas untuk Persyaratan Kerja Akuntan X2

Cronbach's

\begin{tabular}{cc} 
Alpha & $\mathrm{N}$ of Items \\
\hline, 753 & 6 \\
\hline
\end{tabular}

Sumber : Lampiran Output SPSS 26, 2021

Tabel 6. Hasil Uji Reliabilitas untuk Hasil Kerja Akuntan X3

Cronbach's

\begin{tabular}{cc} 
Alpha & $\mathrm{N}$ of Items \\
\hline, 829 & 5 \\
\hline
\end{tabular}

Sumber : Lampiran Output SPSS 26, 2021

Tabel 8. Mahasiswa Y

Cronbach's

Alpha $\quad \mathrm{N}$ of Items




\section{Sumber : Lampiran Output SPSS 26, 2021}

Berdasarkan data tabel di atas bahwa hasil uji reliabilitas statistik Nilai Cronbach's Alpha untuk variabel $\mathrm{X} 1: 0,603$ dari 4 pertanyaan, $\mathrm{X} 2: 0,753$ dari 6 pertanyaan, $\mathrm{X} 3: 0,829$ dari 5 pertanyaan dan Y : 0,830 dari 6 pertanyaan. Maka pertanyaan tersebut dapat dikatakan reliable.

\section{Uji Asumsi Klasik}

Uji Normalitas

Menurut Ghozali (2018:161), Uji normalitas digunakan untuk menentukan apakah variabel terdistribusi atau perubahan model regresi memiliki distribusi normal. Uji normalitas menggunakan metode uji secara visual atau yang lebih sering disebut dengan Normal P-P Plot. Ketentuan dalam melakukan uji normalitas visual adalah dengan cara mengamati jika titik-titik berada pada sekitar garis diagonal maka dinyatakan bahwa data penelitian menyebar secara normal.

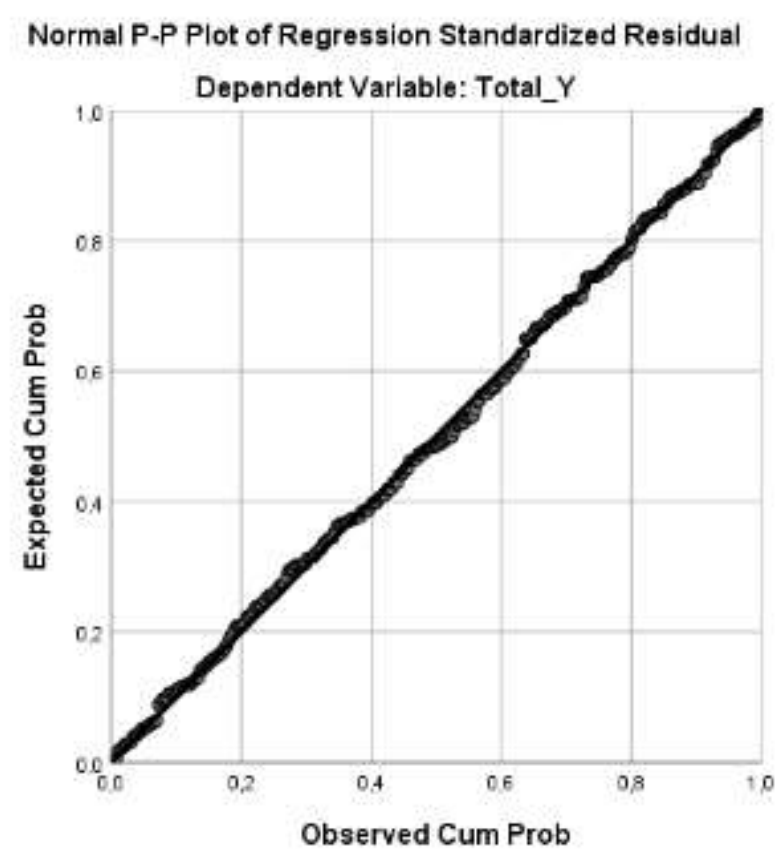

Gambar 2. Hasil Uji Normalitas (Normal P-P Plot) Sumber : Lampiran Output SPSS 26, 2021

Dalam grafik P-P Plot uji normalitas metode visual tersebut dapat dilihat bahwa titik titik tidak terletak jauh dari garis diagonal dan membentuk mengikuti garis diagonalnya, maka dapat dikonklusikan bahwa data menyebar secara normal. 


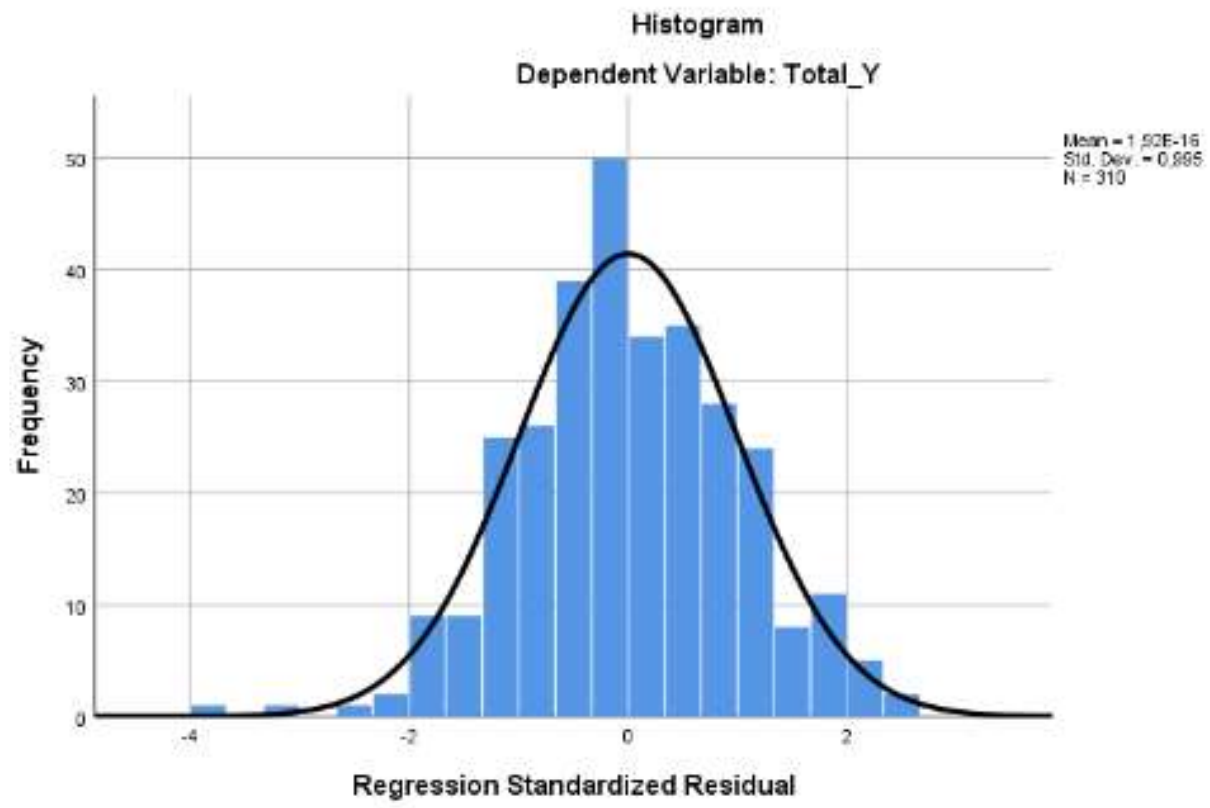

Gambar 3. Hasil Uji Normalitas (Histogram)

Sumber : Lampiran Output SPSS 26, 2021

Hasil kurva histogram diatas dapat kita simpulkan dari model ini berdistribusi normal sebab model ini serupa lonceng, Bell Shaped Curve.

Tabel 8. Hasil Uji Normalitas (Kolmogorov-Smirnov Test)

\section{One-Sample Kolmogorov-Smirnov Test}

\begin{tabular}{llr}
\multicolumn{2}{c}{ One-Sample Kolmogorov-Smirnov Test } \\
\hline \multirow{2}{*}{ Normal Parameters ${ }^{\mathrm{a}, \mathrm{b}}$} & & $\begin{array}{c}\text { Unstandardize } \\
\text { d Residual }\end{array}$ \\
& Mean & 310 \\
& Std. &, 0000000 \\
Most Extreme Differences & Deviation & 2,73503836 \\
& Absolute &, 027 \\
& Positive &, 027 \\
Test Statistic & Negative &,- 022 \\
Asymp. Sig. (2-tailed) & &, 027 \\
\hline \multicolumn{2}{c}{ Sumber : Lampiran Output SPSS 26, 2021 } \\
\multicolumn{2}{c}{ Sum }
\end{tabular}

Berdasarkan tabel diatas dapat disimpulkan nilai Asymp. Sig. (2-tailed) sebesar 0,200 > 0,05. Maka model mempunyai data berdistribusi normal.

\section{Uji Multikolinearitas}

Menurut Ghozali (2018:107), uji multikolinearitas dibuat untuk uji apakah model regresi menyampaikan kaitan antara variabel bebas (independen).

Tabel 7. Hasil Uji Multikolinearitas

\begin{tabular}{llrr} 
& \multicolumn{2}{c}{ Collinearity Statistics } \\
Model & & \\
\hline 1 (Colerance & VIF \\
Profesi_Akuntan & 906 & 1,104 \\
Persyaratan_Kerja_Akuntan &, 900 & 1,112
\end{tabular}




\section{$\frac{\text { Hasil_Kerja_Akuntan }}{\text { Sumber : Lampiran Output SPSS 26, } 2021}$}

Berdasarkan Tabel 7. Nilai VIF dari X1 sebesar 1,104 < 10, X2 sebesar 1,112 < 10, X3 sebesar $1,125<10$. Serta nilai tolerance X1 sebesar 0,906 >0,10, X2 sebesar 0,900 >0,10, dan $\mathrm{X} 3$ sebesar 0,889 >0,10, sehingga ditarik kesimpulan tidak terjadi multikolinearitas antara variabel bebas.

\section{Uji Heteroskedastisitas}

Menurut Ghozali (2018:137) mengungkapkan pada uji ini berguna mengetahui apakah ada perbedaan fragmen dan model regresi dari satu pengamatan ke pengamatan lain.

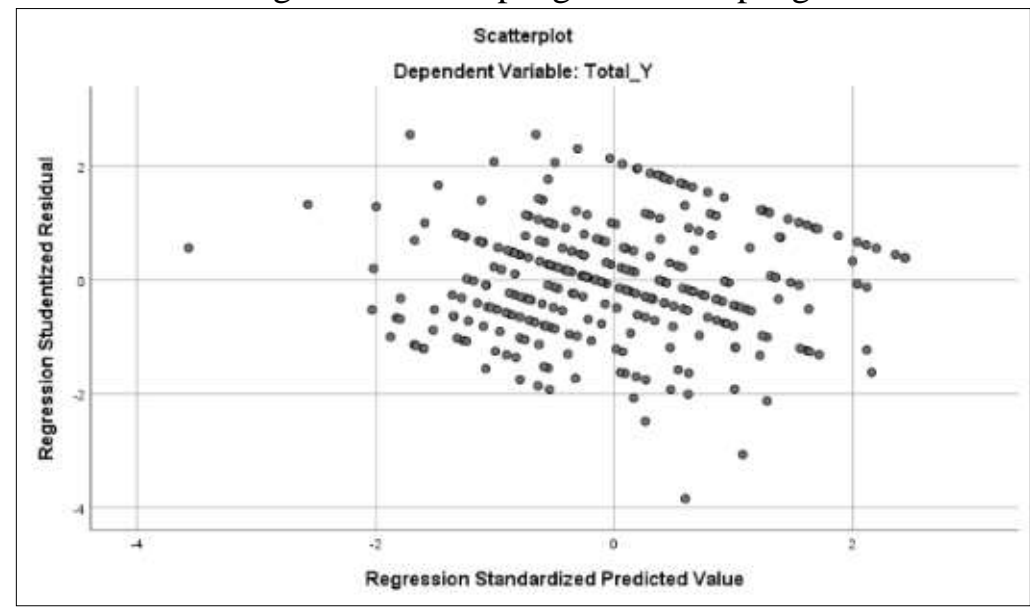

Gambar 1. Hasil Uji Heteroskedastisitas

Sumber : Lampiran Output SPSS 26, 2021

Berdasarkan gambar 1 diatas bisa dicermati pada titik-titik grafik menyebar dan tidak memunculkan bentuk suatu pola gelombang. Pada titik-titik menyebar secara acak baik di atas ataupun di bawah poin 0 pada sumbu y maka dapat di ambil kesimpulan tidak terdapat gejala heteroskedastisitas.

\section{Hasil Analisis Regresi Linier Berganda}

Suatu metode statistik yang dipakai untuk memperkirakan nilai suatu variabel terikat berlandaskan nilai dua atau lebih variabel bebas.

Tabel 9. Hasil Analisis Regresi Linier Berganda
Unstandardized
Standardized
Coefficients
Coefficients

Std.

\begin{tabular}{|c|c|c|c|c|c|}
\hline Model & $\mathrm{B}$ & Error & Beta & $\mathrm{t}$ & Sig. \\
\hline 1 (Constant) & 6,686 & 1,589 & & 4,207 & ,000 \\
\hline Profesi_Akuntan & ,152 & ,077 & ,098 & 1,982 & ,048 \\
\hline Persyaratan_Kerja_Akuntan & ,380 &, 051 & ,372 & 7,514 & 000 \\
\hline Hasil_Kerja_Akuntan & ,313 & 052 & 297 & 5,975 & ,000 \\
\hline
\end{tabular}

Sumber : Lampiran Output SPSS 26, 2021

Persamaan regresi berupa :

$\mathrm{Y}=6,686+0,152+0,380+0,313$

1. Konstanta sebesar 6,686, hal ini menunjukan jika profesi akuntan (X1) bernilai 0,048, persyaratan kerja akuntan $(X 2)$ bernilai 0,000 , dan hasil kerja akuntan 0,000 maka mahasiswa (Y) memiliki nilai 6,686.

2. Koefisien variabel profesi akuntan (X1) sebesar 0,152 dan terdapat hubungan positif antara profesi akuntan (X1) dengan mahasiswa (Y). Maksudnya profesi akuntan berpengaruh secara 
signifikan terhadap mahasiswa sehingga hipotesis pertama (H1) terbukti dan dapat diterima.

3. Koefisien variabel persyaratan kerja akuntan (X2) sebesar 0,380 dan bernilai positif berarti terdapat hubungan positif antara persyaratan kerja akuntan (X2) dengan mahasiswa (Y). Maksudnya persyaratan kerja akuntan berpengaruh secara signifikan terhadap mahasiswa sehingga hipotesis kedua (H2) terbukti dan dapat diterima.

4. Koefisien variabel hasil kerja akuntan (X3) sebesar 0,313 dan terdapat hubungan positif antara hasil kerja akuntan (X3) dengan mahasiswa (Y). Maksudnya hasil kerja akuntan berpengaruh signifikan terhadap mahasiswa sehingga hipotesis ketiga (H3) terbukti dan dapat diterima.

Dari tabel 9 menunjukkan bahwa perbandingan nilai koefisien regresi antara profesi akuntan (X1) sebesar 0,152, persyaratan kerja akuntan (X2) 0,380 dan hasil kerja akuntan (X3) 0,313. Dapat disimpulkan bahwa persyaratan kerja akuntan (X2) lebih mendominasi terhadap mahasiswa (Y).

\section{Uji Hipotesis}

Uji t (Parsial)

Uji parsial juga disebutkan sebagai Uji T. Menurut Ghozali (2016:171) fungsi uji T adalah jadikan alat uji efek dari variabel independen terhadap variabel dependen pada sebuah model penelitian. Nilai signifikansi bahwa profesi akuntan, persyaratan kerja akuntan dan hasil kerja akuntan menunjukkan nilai kurang dari 0.05 , dapat diucapkan ketiga variabel independen memiliki pengaruh yang signifikan terhadap variabel dependennya.

\begin{tabular}{|c|c|c|c|c|c|}
\hline \multirow[b]{3}{*}{ Model } & \multicolumn{3}{|c|}{ Tabel 10. Hasil Uji t } & & \multirow[b]{3}{*}{ Sig. } \\
\hline & \multicolumn{2}{|c|}{$\begin{array}{c}\text { Unstandardized } \\
\text { Coefficients } \\
\text { Std. }\end{array}$} & $\begin{array}{l}\text { Standardized } \\
\text { Coefficients }\end{array}$ & & \\
\hline & $\mathrm{B}$ & Error & Beta & $\mathrm{t}$ & \\
\hline 1 (Constant) & 6,686 & 1,589 & & 4,207 & 000 \\
\hline Profesi_Akuntan &, 152 & ,077 & ,098 & 1,982 &, 048 \\
\hline Persyaratan_Kerja_Akuntan & ,380 & 051 & ,372 & 7,514 & 000 \\
\hline Hasil_Kerja_Akuntan & ,313 & 052 & ,297 & 5,975 & 000 \\
\hline
\end{tabular}

Dengan tingkat signifikan 0,05 dan 2 sisi dengan derajat kebebasan df $(n-k-1)=310-3-1=$ 306 maka diperoleh nilai $t$ tabel sebesar 1,968. Diperoleh kesimpulan berupa :

H1 : Variabel profesi akuntan dideteksi mendapatkan nilai t hitung 1,982 > 1,968 (t tabel) dan nilai signifikan $0,048<0,05$. Dapat disimpulkan diterimanya $\mathrm{Ha}$ serta ditolaknya Ho, sehingga dapat dikatakan diterimanya $\mathrm{H} 1$.

H2 : Variabel persyaratan kerja akuntan dideteksi mendapatkan nilai t hitung 7,514 > 1,968 (t tabel) dan nilai signifikan $0,000<0,05$. Dapat disimpulkan diterimanya $\mathrm{Ha}$ serta ditolaknya Ho, sehingga dapat dikatakan diterimanya $\mathrm{H} 2$.

H3 : Variabel hasil kerja akuntan dideteksi mendapatkan nilai t hitung 5,514 > 1,968 (t tabel) dan nilai signifikan $0,000<0,05$. Dapat disimpulkan diterimanya $\mathrm{Ha}$ serta ditolaknya Ho, sehingga dapat dikatakan diterimanya $\mathrm{H} 3$. 
Menurut Ghozali (2016:171) uji simultan juga disebut Uji F sebagai alat penguji secara simultan berpengaruh variabel independen terhadap variabel dependen.

\begin{tabular}{|c|c|c|c|c|c|c|}
\hline \multirow[b]{2}{*}{ Model } & \multicolumn{6}{|c|}{ Tabel 11. Hasil Uji f } \\
\hline & & $\begin{array}{l}\text { Sum of } \\
\text { Squares }\end{array}$ & $\mathrm{df}$ & Mean Square & $\mathrm{F}$ & Sig. \\
\hline \multirow[t]{3}{*}{1} & Regression & 1122,433 & 3 & 374,144 & 49,531 &, $000^{\mathrm{b}}$ \\
\hline & Residual & 2311,454 & 306 & 7,554 & & \\
\hline & Total & 3433,887 & 309 & & & \\
\hline
\end{tabular}

Sumber : Lampiran Output SPSS 26, 2021

Nilai signifikan profesi akuntan (X1), persyaratan kerja akuntan (X2) dan hasil kerja akuntan (X3) terhadap mahasiswa (Y) yaitu sebesar $0,000<$ dari 0,05 dan $\mathrm{F}$ hitung sebesar 49,531 > dari nilai F tabel 2,63. Peristiwa ini menunjukkan Ho tidak disetujui dan Ha disetujui. Sehingga dapat dikatakan secara simultan profesi akuntan, persyaratan kerja akuntan dan hasil kerja akuntan signifikan terhadap mahasiswa.

\section{Uji Koefisien Determinasi $\left(\mathbf{R}^{2}\right)$}

Menurut Ghozali, (2016:171), koefisien determinasi $\left(\mathrm{R}^{2}\right)$ dipakai untuk pengujian goodness-fit dalam model regresi. Tabel pada model summary merupakan tempat terletaknya koefisien determinasi yang diformulasikan dalam $\mathrm{R}^{2}$ yang tersaji pada output SPSS.

Tabel 12. Hasil Uji Koefisien Determinasi ( $R$ Squared)

\begin{tabular}{lllll} 
Model & $\mathrm{R}$ & $\mathrm{R}$ Square & $\begin{array}{l}\text { Adjusted } \\
\text { Square }\end{array}$ & $\begin{array}{l}\text { R Std. Error of } \\
\text { the Estimate }\end{array}$ \\
\hline 1 &, $572^{\mathrm{a}}$ &, 327 &, 320 & 2,748 \\
\hline \multicolumn{4}{c}{ Sumber : Lampiran Output SPSS 26, 2021}
\end{tabular}

Berdasarkan tabel diatas, dapat dilihat nilai Adjusted R Square dengan variable dependen profesi akuntan yaitu 0,320 atau $32,0 \%$. Angka tersebut menunjukkan bahwa variabel independen seperti profesi akuntan, persyaratan pekerjaan akuntan dan hasil pekerjaan akuntan dapat menjelaskan variabel dependen yaitu mahasiswa sebesar 32,0\%. Sedangkan 68,0\% akan dijelaskan oleh faktor lain.

\section{PEMBAHASAN}

\section{Pengaruh Profesi Akuntan terhadap Mahasiswa di kota Batam}

Dari hasil yang diperhitungkan memunculkan hasil 1,982 merupakan nilai t hitung > 1,968 hasil $\mathrm{t}$ tabel, kemudian dengan hasil nilai signifikan $0,048<0,05$ sehingga secara parsial profesi akuntan berpengaruh signifikan terhadap mahasiswa di kota Batam. Kemudian perhitungan menggunakan uji $\mathrm{F}$ mendapatkan hasil bahwa nilai $\mathrm{f}$ hitung 49,531 > 2,63 nilai $\mathrm{F}$ tabel dengan nilai signifikansi sebesar 0,000 nilai ini < dari 0,05 , maka dapat dikatakan profesi akuntan berpengaruh signifikan terhadap mahasiswa di kota Batam. Dari hasil penelitian oleh Karina \& Wijaya (2021) dan Itan \& Gabriela (2021) yang menguji gambaran profesi akuntan terhadap pemilihan karir akuntan publik dan akuntan perusahaan dengan hasil analisis adalah gambaran profesi akuntan berpengaruh signifikan pemilihan karir akuntan publik dan akuntan perusahaan.

\section{Pengaruh Persyaratan Kerja Akuntan terhadap Mahasiswa di kota Batam}

Dari hasil yang diperhitungkan memunculkan hasil 7,514 merupakan nilai t hitung > 1,968 hasil $\mathrm{t}$ tabel, kemudian dengan hasil nilai signifikan $0,000<0,05$ sehingga secara parsial profesi akuntan berpengaruh signifikan terhadap mahasiswa di kota Batam. Kemudian perhitungan menggunakan uji $\mathrm{F}$ mendapatkan hasil bahwa nilai $\mathrm{f}$ hitung 49,531 > 2,63 nilai $\mathrm{F}$ tabel dengan nilai signifikansi sebesar 0,000 nilai ini < dari 0,05, maka dapat dikatakan profesi akuntan berpengaruh signifikan terhadap mahasiswa di kota Batam. Dari hasil penelitian oleh Karina \& Wijaya (2021) dan Itan \& Gabriela (2021) yang menguji gambaran profesi akuntan 
terhadap pemilihan karir akuntan publik dan akuntan perusahaan dengan hasil analisis adalah gambaran profesi akuntan berpengaruh signifikan pemilihan karir akuntan publik dan akuntan perusahaan.

\section{Pengaruh Hasil Kerja Akuntan terhadap Mahasiswa di kota Batam}

Dari hasil yang diperhitungkan memunculkan hasil 5,975 merupakan nilai t hitung > 1,968 hasil $\mathrm{t}$ tabel, kemudian dengan hasil nilai signifikan $0,000<0,05$ sehingga secara parsial hasil kerja akuntan berpengaruh signifikan terhadap mahasiswa di kota Batam. Kemudian perhitungan menggunakan uji $\mathrm{F}$ mendapatkan hasil bahwa nilai $\mathrm{f}$ hitung 49,531 > 2,63 nilai $\mathrm{F}$ tabel dengan nilai signifikansi sebesar 0,000 nilai ini < dari 0,05, maka dapat dikatakan hasil kerja akuntan berpengaruh signifikan terhadap mahasiswa di kota Batam. Dari hasil penelitian oleh Karina \& Wijaya (2021) dan Itan \& Gabriela (2021) yang menguji hasil perkerjaan akuntan terhadap pemilihan karir akuntan publik dan akuntan perusahaan dengan hasil analisis adalah hasil perkerjaan akuntan berpengaruh signifikan pemilihan karir akuntan publik dan akuntan perusahaan.

\section{Pengaruh Profesi, Persyaratan kerja dan Hasil kerja akuntan terhadap Mahasiswa di kota Batam}

Perhitungan menggunakan Uji $\mathrm{F}$ bahwa pengaruh profesi akuntan, persyaratan kerja dan hasil kerja akuntan Nilai $F$ hitung sebesar 49,531 > dari $F$ tabel sebesar 2,63 dengan nilai signifikansi sebesar 0,000 nilai ini < dari 0,05 maka dapat dikatakan simpulan secara simultan profesi akuntan, persyaratan kerja akuntan dan hasil kerja akuntan berpengaruh signifikan terhadap mahasiswa di kota Batam. Dari hasil penelitian oleh Karina \& Wijaya (2021) dan Itan \& Gabriela (2021) yang menguji hasil perkerjaan akuntan terhadap pemilihan karir akuntan publik dan akuntan perusahaan dengan hasil analisis adalah hasil gambaran profesi akuntan, persyaratan kerja akuntan dan hasil kerja akuntan berpengaruh signifikan pemilihan karir akuntan publik dan akuntan perusahaan.

\section{KESIMPULAN}

Pada penelitian yag telah dilakukan pada mahasiswa akuntansi di kota Batam, peneliti menarik kesimpulan bahwa profesi akuntan berupa gambaran, persyaratan kerja akuntan dan hasil kerja akuntan berupa penghargaan finansial berpengaruh secara signifikan secara parsial dan simultan. Pada penelitian ini bahwa mahasiswa akuntansi lebih mementingkan persyaratan kerja akuntan yang sangat sulit untuk menjadi akuntan publik.

\section{REFERENSI}

Alvin Juliansah, \& Rossje V Suryaputri. (2016). Perbedaan Persepsi Antar Mahasiswa Senior Dan Mahasiswa Junior Mengenai Profesi Akuntan Pada Program S-1 Akuntansi Di Universitas Islam Kuantan Singingi. D, 3, 113-134.

Astuti, F. D., \& Andri Waskita Aji. (2021). Terhadap Minat Mahasiswa Akuntansi Menjadi Akuntan Publik (Studi Kasus Pada Mahasiswa Jurusan Akuntansi Program S1 Universitas Sarjanawiyata Tamansiswa Yogyakarta). 4(1). http://ejurnal.unim.ac.id/index.php/prive

Boateng, J. C. (2019). Chinese Tertiary Accounting Student's Perceptions of Certified Public Accountants and Their Career Job Choice. Finance and Accounting, 10(16). https://doi.org/10.7176/RJFA

Danar Sutopo Sidig, \& Andar Ramona Sinaga. (2020). What Explains Students' Intentions To Pursue Public Accountants As a Career? Jurnal Akuntansi Dan Keuangan Indonesia, 17(1). https://doi.org/10.21002/jaki.2020.03

Ghozali, I. (2016). Aplikasi Analisis Multivariete Dengan Program IBM SPSS 23 (Edisi 8). Badan Penerbit Universitas Diponegoro.

Ghozali, I. (2018). Aplikasi Analisis Multivariate dengan Program IBM SPSS 25 (Badan Penerbit Universitas Diponegoro. (ed.)). Badan Penerbit Undip.

Handoko, H. (2014). Manajemen Personalia Dan Sumber Daya Manusia Edisi Dua. BPFE.

Itan, I., \& Gabriela. (2021). Persepsi Mahasiswa Akuntansi Terhadap Profesi Akuntan di Kota Batam (Vol. 1, Issue 1). https://journal.uib.ac.id/index.php/combines 
Karina, R., \& Wijaya, M. P. (2021). Analisis pengaruh persepsi mahasiswa akuntansi terhadap profesi akuntan di kota Batam. CoMBInES-Conference on Management Business Innovation Education and Social Science, l(1), 1701-1711. https://journal.uib.ac.id/index.php/combines/article/view/4558

Kristina, \& Argo Putra Prima. (2020). Analisis Faktor-Faktor Yang Mempengaruhi Pemilihan Karir Sebagai Akuntan Publik Pada Mahasiswa Akuntansi di Kota Batam. 425.

Mirawati. (2017). Pengaruh Motivasi Terhadap Minat Pemilihan Karir Mahasiswa Akuntansi Sebagai Akuntan Publik.

Purba, M. A., \& Yando, A. D. (2020). Revolusi Industri 4.0. Cv Batam Publisher. https://books.google.co.id/books?id=BRAREAAAQBAJ\&printsec $=$ frontcover\&hl $=\mathrm{id} \# \mathrm{v}=\mathrm{o}$ nepage $\& \mathrm{q} \& \mathrm{f}=$ false

Setiany, E., Hartoko, S., Suhardjanto, D., \& Honggowati, S. (2018). Audit Committee Characteristics and Audit- Earnings Quality: Empirical Evidence of the Company with Concentrated Ownership. Review of Integrative Business and Economics Research, 7(Supplementary Issue 1), 18-33. https://search.proquest.com/docview/1969779323/fulltextPDF/48FDC91C1AC642DCPQ/2 7 ? accountid $=31731$

Sugiyono. (2010). Metode penelitian pendidikan: pendekatan kuantitatif, kualitatif, dan R\&D. Alfabeta.

Sugiyono. (2018). Metode Penelitian Pendidikan (Pendekatan Kuantitatif, Kualitatif, Dan R\&D) (Alfabeta (ed.)). 